\title{
Analisis Hiraaspek Keselamatan dan Kesehatan Kerja (K3) di Laboratorium Motor Bakar Politeknik Negeri Subang
}

\author{
Adhan Efendi ${ }^{1)}$, Yohanes Sinung Nugroho ${ }^{2)}$, Muhammad Fahmi ${ }^{3)}$ \\ ${ }^{1,3)}$ Politeknik Negeri Subang \\ ${ }^{2)}$ Politeknik Negeri Bandung \\ Email : ${ }^{1)} \frac{\text { adhan@ @olsub.ac.id, }}{{ }^{2)} \text { fahmialons76@ sinung.polban@ @mail.com }}$
}

\begin{abstract}
Abstrak
Penelitian ini merupakan penelitian analisis. Tahapan penelitian di mulai dengan tim peneliti melakukan observasi menggunakan metode HIRA di laboratorium motor bakar Politeknik Negeri Subang. Data yang didapatkan kemudian di analisis dengan pengukuran yang digunakan dalam Australian Standard/New Zealand Standard (AS/NZS). Berdasarkan hasil temuan dan analisis, dapat disimpulkan bahwa (1) ditemukan 9 bahaya (hazard) di laboratorium motor bakar Politeknik Negeri Subang. Dari 9 bahaya tersebut terdiri dari 1 bahaya dalam kategori 3H (high) yaitu penempatan posisi motor terlalu berdekatan dan tidak menggunakan APD; 2 bahaya dalam kategori 2M (medium), dan 6 bahaya masuk kategori L (low). Tidak ada yang masuk dalam kategori bahaya ekstrem; (2) Rekomendasi tindakan yang bisa dilakukan untuk mengurangi bahaya di laboratorium motor bakar Politeknik Negeri Subang yaitu pembuatan SOP laboratorium, penataan kembali tata ruang dan peralatan, serta pemberian instruksi sebelum dan sesudah mahasiswa praktikum.
\end{abstract}

Kata Kunci: HIRA, Keselamatan dan Kerja (K3), Motor Bakar.

\begin{abstract}
This research is an analytical research. The research stage began with the research team making observations using the HIRA method in the fuel motor laboratory of the Subang State Polytechnic. The data obtained were then analyzed with measurements used in the Australian Standard / New Zealand Standard (AS / NZS). Based on the findings and analysis, it can be concluded that (1) 9 hazards were found in the fuel motor laboratory of the Subang State Polytechnic. Of the 9 hazards, 1 hazard is in the 3H (high) category, namely placing the motorbike too close together and not using PPE; 2 hazards in the $2 M$ (medium) category, and 6 hazards in the L (low) category. None of them fall into the category of extreme danger; (2) Recommendations for actions that can be taken to reduce hazards in the fuel motor laboratory of the Subang State Polytechnic, namely making laboratory SOPs, rearranging spatial planning and equipment, as well as giving instructions before and after practicum students.
\end{abstract}

Keywords: HIRA, Combustion Engine, Safety and Health Work 


\section{PENDAHULUAN}

Politeknik merupakan lembaga pendidikan kejuruan tingkat perguruan tinggi yang terfokus pada pengembangan kompetensi peserta didiknya untuk bersaing secara global. Menurut A. Efendi \& Y. SinungPembelajaran di pendidikan kejuruan terdiri dari teori dan praktik yang bertujuan untuk meningkatkan kompetensi [1]. Salah satu Politeknik yang sedang berkembang di Provinsi Jawa barat yaitu Politeknik Negeri Subang.Politeknik Negeri Subang memiliki Program Studi Pemeliharaan Mesin. Program Studi ini terfokus pada pembekalan kompetensi mahasiswanya di bidang pemeliharaan mesin-mesin industri. Mata kuliah praktik motor bakar menjadi salah satu mata kuliah yang di praktikkan di laboratorium.

Kecelakaan kerja dapat berlangsung dimanapun, dan kapanpun. Menurut Dian [2] mahasiswa menjadi sumber daya penting yang harus di lindungi disaat proses pratikum berlangsung. Setiap praktikum yang berlangsung memiliki resiko mengalami kecelakaan [3]. Ditambahkan oleh Cindy [4] mencegah dan mengurangi risiko yang mungkin timbul dalam melakukan aktivitas kerja, itu harus diatasi dengan upaya. Yang terpenting kita yang harus dilakukan untuk mengendalikan kecelakaan kerja adalah dengan mengidentifikasi bahaya. Identifikasi Bahaya dan Penilaian Risiko (HIRA) adalah salah satu metode digunakan untuk mengidentifikasi bahaya dalam aktivitas kerja.HIRA adalah serangkaian proses mengidentifikasi bahaya yang dapat terjadi dalam aktifitas rutin ataupun non rutin di suatu instansi, kemudian melakukan penilaian risiko dari bahaya tersebut lalu membuat program pengendalian bahaya tersebut agar dapat diminimalisir tingkat risikonya ke yang lebih rendah dengan tujuan mencegah terjadi kecelakaan. Ditambahkan oleh Ade, Ani dan Febi [5] proses identifikasi menggunakan HIRA ini adalah sebagai berikut: (1) Identifikasi Bahaya; (2) Risk Assessment (Analisa resiko) dan (3) Determine Controls (Menetapkan tindakan pengendalian).

Risiko terjadinya kecelakaan dan penyakit akibat kerja dapat meningkat apabila didukung oleh lingkungan kerja yang tidak memenuhi syarat Keselamatan dan Kesehatan Kerja [6]. Berdasarkan hasil observasi tim peneliti di laboratorium

\footnotetext{
Analisis Hiraaspek Keselamatan dan Kesehatan Kerja (K3) di Laboratorium Motor Bakar Politeknik Negeri Subang

(Adhan Efendi, Yohanes Sinung Nugroho, Muhammad Fahmi)
} 
motor bakar Politeknik Negeri Subang, didapati beberapa temuan bahwa masih terjadi kecelakaan kerja dalam tingkat rendah dan medium.

Kecelakaan kerja yang dialami oleh mahasiswa disaat praktik, umumnya disebabkan kelalaian dan faktor lingkungan yang belum menunjang proses praktikum secara maksimal. Penelitian ini bertujuan untuk menganalisis aspek keselamatan dan kesehatan kerja dengan metode HIRA di laboratorium motor bakar Politeknik Negeri Subang. Pemilihan laboratorium motor bakar, dikarenakan laboratorium tersebut sering mendapat keluhan dari mahasiswa mengenai standar-standar keselamatan dan kesehatan kerja yang belum diterapkan secara optimal.

Analisis HIRA diharapkan dapat mencegah terjadinya kecelakaan kerja di laboratorium motor bakar Politeknik Negeri Subang. Ditambahkan oleh [7] upaya mencegah terjadinya kecelakaan kerja perlu dilakukan pemetaan risiko dan bahaya. Potensi bahaya disebut sebagai hazard. Hampir di setiap tempat dimana berlangsunya suatu aktivitas/kegiatan, baik di rumah, di jalan, maupun di tempat kerja. Jika hazard tidak dikendalikan dengan tepat, maka akan menyebabkan kelelahan, sakit, cedera, dan kecelakaan kerja.

\section{METODE PENELITIAN}

Tahapan penelitian di mulai dengan tim peneliti melakukan observasi menggunakan metode HIRA di laboratorium motor bakar Politeknik Negeri Subang. Data yang didapatkan kemudian di analisis dengan pengukuran yang digunakan dalam Australian Standard/New Zealand Standard (AS/NZS). Ditambahkan oleh Rico W [8]Analisis Risiko dalam manajemen risiko adalah proses menilai (assessment)dampak dan kemungkinan dari risiko yang sudah di identifikasi. Proses ini dilakukan dengan menyusun risiko berdasarkan efeknya terhadap tujuan pratikum. HIRA dilakukan sesuai urutan proses kerja dari awal sampai akhir yang bertujuan menemukan apa yang mungkin bisa menyebabkan kecelakaan besar (identifikasi bahaya), bagaimana mungkin itu adalah bahwa kecelakaan besar akan terjadi dan konsekuensi potensial (penilaian risiko) dan pilihan apa yang ada untuk mencegah dan mengurangi kecelakaan besar [9]. Implementasi HIRA dimulai dengan dengan urutan sebagai berikut: 
1. Memahami prosedur praktikum di laboratorium motor bakar

2. Identifikasi bahaya di laboratorium motor bakar berdasarkan pengamatan, wawancara, dan pengukuran. Identifikasi bahaya termasuk lokasi, foto-foto kegiatan hubungan, deskripsi temuan bahaya, risiko dan sumber bahaya dari awal hingga akhir proses untuk memahami semua penyimpangan yang terjadi.

3. Melakukan penilaian risiko terhadap bahaya yang telah terjadi diidentifikasi untuk menentukan tingkat keparahan atau bahaya apa pun yang memiliki risiko terbesar.

Diperjelas oleh Bambang Suhardi et al [10] setelah pengamatan menggunakan metode HIRA, hasil temuan harus dianalisis menggunakan matriks analisis resiko keselamatan dan kesehatan kerja. Analisis hira diharapkan mampu mengurangi resiko kecelakaan yang terjadi di laboratorium bidang pendidikan [11].

Berikut tabel matriks yang digunakan di dalam penelitian ini:

Tabel 1. matriks analisis risiko menurut standar AS/NZS 4360

\begin{tabular}{|c|c|c|c|c|c|}
\hline $\begin{array}{c}\text { Frekuensi } \\
\text { Resiko }\end{array}$ & \multicolumn{5}{|c|}{ Dampak Resiko } \\
\hline 5 & H & H & E & E & E \\
\hline 4 & M & H & H & E & E \\
\hline 3 & L & M & H & E & E \\
\hline 2 & L & L & M & H & E \\
\hline 1 & L & L & M & H & H \\
\hline
\end{tabular}

Menurut Standar AS/NZS 4360

E: Ekstrim Risk - Tidak dapat ditoleransi sehingga perlu penanganan dengan segera.

H: High Risk - Risiko yang tidak diinginkan, hanya dapat diterima jika pengurangan risiko tidak dapat dilaksanakan sehingga perlu perhatian khusus dari pihak manajemen.

Analisis Hiraaspek Keselamatan dan Kesehatan Kerja (K3) di Laboratorium Motor Bakar Politeknik Negeri Subang

(Adhan Efendi, Yohanes Sinung Nugroho, Muhammad Fahmi) 
M: Moderate Risk - Risiko yang dapat diterima namun memerlukan tanggung jawab yang jelas dari manajemen.

L: Low Risk - Risiko yang dapat diatasi dengan prosedur yang rutin.

\section{HASIL DAN PEMBAHASAN}

Tim peneliti melakukan observasi di laboratorium motor bakar Politeknik Negeri Subang dilaksanakan mulai tanggai 12 Desember 2019-3 Februari 2020. Beberapa bahaya(hazard) yang ditemukan adalah sebagai berikut:

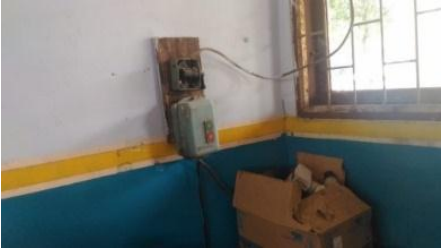

Gambar 1. sistem kelistrikan lab

Ditemukan sistem kelistrikan di laboratorium motor bakar yang tidak memiliki tutup dan kabel yang terurai.

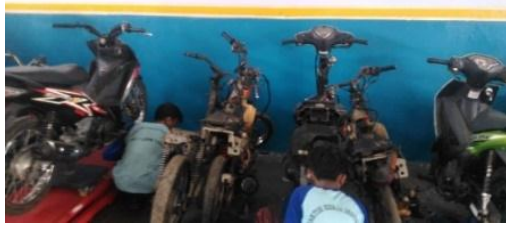

Gambar 2. standar APD

Penempatan posisi motor praktik yang terlalu berdekatan dan tanpa penggunaan alat pelindung diri (APD).

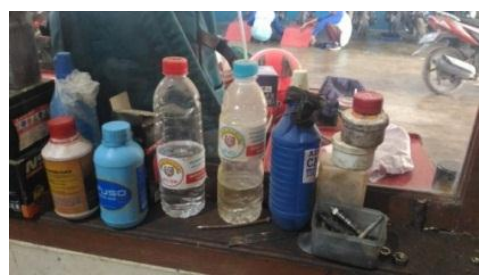

Gambar 3. peletakan bahan cair

Bahan dan peralatan pratikum yang menggandung cairan kimia ditempatkan tidak sesuai (tidak ada tempat khusus untuk bahan/peralatan yang menggandung cairan kimia) 


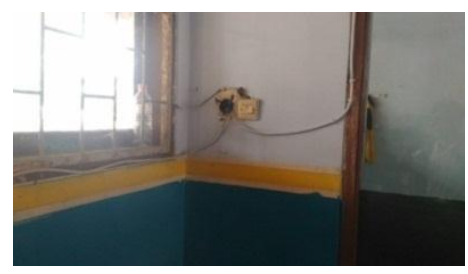

Gambar 4. stop kontak lab

Kabel stop kontak yang panjang dan tidak dilengkapi dengan cable duct/tray cable.

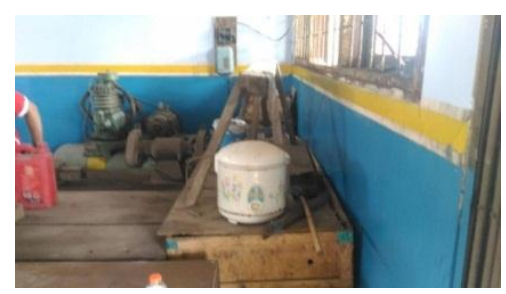

Gambar 5. penempatan barang pribadi

Penempatan barang-barang pribadi teknisi yang sembarangan (tidak pada tempat khusus alat-alat pribadi).

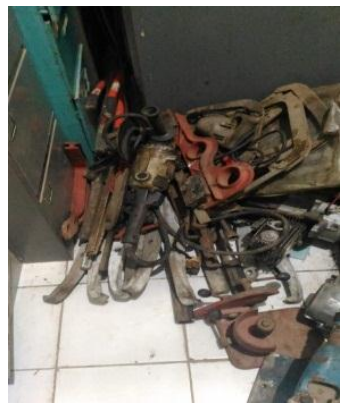

Gambar 6. alat pratikum

Sebelum dan sesudah praktikum, peletakan alat pratikum yang tidak pada tempatnya.

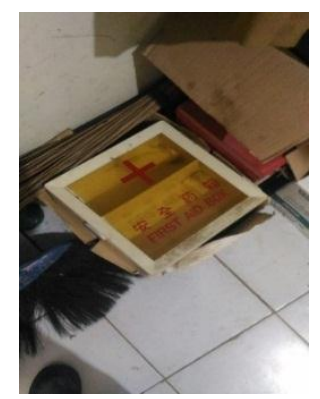

Gambar 7. perlengkapan P3K

Peralatan P3K diletakan di lantai dan tidak mengikuti standar keamanan dan kesiagaan ruang laboratorium.

Analisis Hiraaspek Keselamatan dan Kesehatan Kerja (K3) di Laboratorium Motor Bakar Politeknik Negeri Subang

(Adhan Efendi, Yohanes Sinung Nugroho, Muhammad Fahmi) 


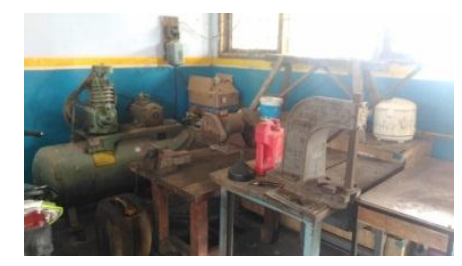

Gambar 8. tata letak peralatan

Peletakan tata letak atau posisi alat yang tidak sesuai dan menghambat proses pratikum.

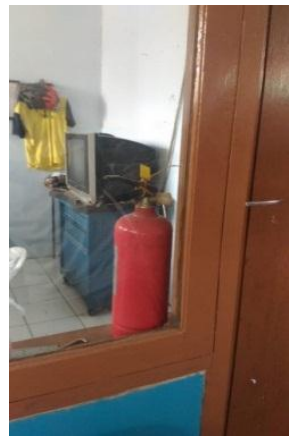

Gambar 9. peralatan APAR

Peletakan posisi APAR yang tidak sesuai dan memungkinkan menjadi hambatan ketika terjadi kebakaran di laboratorium motor bakar.

Tabel 2. analisis HIRA dengan standar AS/NZS 4360

\begin{tabular}{|c|c|c|c|c|c|}
\hline No & $\begin{array}{l}\text { Hazard } \\
\text { (Bahaya) }\end{array}$ & Risk (Resiko) & Penyebab & $\begin{array}{c}\text { Kategori } \\
\text { Resiko }\end{array}$ & Rekomendasi \\
\hline \multirow[t]{2}{*}{1} & \multirow[t]{2}{*}{$\begin{array}{l}\text { Kelistrikan } \\
\text { tidak } \\
\text { memiliki } \\
\text { tutup dan } \\
\text { kabel yang } \\
\text { terurai. }\end{array}$} & $\begin{array}{l}\text { 1. Dapat } \\
\text { menyebabk } \\
\text { an } \\
\text { mahasiswa } \\
\text { tersandung } \\
\text { kabel }\end{array}$ & $\begin{array}{l}\text { 1. Kurangny } \\
\text { a } \\
\text { pengawas } \\
\text { an } \\
\text { terhadap } \\
\text { sistem } \\
\text { kelistrikan }\end{array}$ & $2 \mathrm{M}$ & \multirow{2}{*}{ 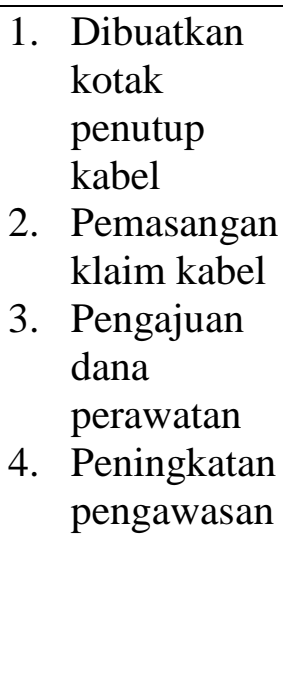 } \\
\hline & & 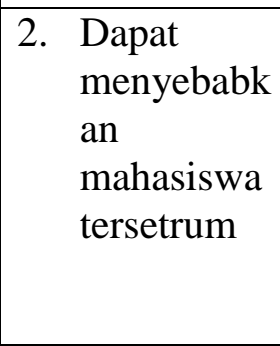 & $\begin{array}{l}\text { 2. Kurangny } \\
\text { a dana } \\
\text { dan } \\
\text { tindakan } \\
\text { perawatan } \\
\text { laboratori } \\
\text { um }\end{array}$ & & \\
\hline 2 & $\begin{array}{l}\text { Penempatan } \\
\text { posisi motor } \\
\text { terlalu }\end{array}$ & 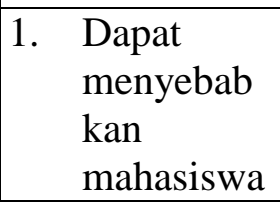 & $\begin{array}{l}\text { 1. Lokasi } \\
\text { letak } \\
\text { motor } \\
\text { yang }\end{array}$ & $3 \mathrm{H}$ & $\begin{array}{l}\text { 1. Mengatur } \\
\text { ulang posisi } \\
\text { motor } \\
\text { praktikum }\end{array}$ \\
\hline
\end{tabular}




\begin{tabular}{|c|c|c|c|c|c|c|}
\hline & \multirow{2}{*}{$\begin{array}{l}\text { berdekatan } \\
\text { dan tidak } \\
\text { menggunakan } \\
\text { APD }\end{array}$} & \multicolumn{2}{|r|}{$\begin{array}{l}\text { tertimpa } \\
\text { motor }\end{array}$} & \begin{tabular}{|l|l}
$\begin{array}{l}\text { terlalu } \\
\text { berdekata } \\
n\end{array}$ \\
2. & Kurangny
\end{tabular} & & \multirow{2}{*}{$\begin{array}{l}\text { 2. } \text { Melakukan } \\
\text { pengawasan } \\
\text { pada saat } \\
\text { mahasiswa } \\
\text { melakukan } \\
\text { pratikum }\end{array}$} \\
\hline & & 2 & $\begin{array}{l}\text { Dapat } \\
\text { menyebab } \\
\text { kan } \\
\text { kerusakan } \\
\text { pada mesin } \\
\text { praktikum } \\
\end{array}$ & $\begin{array}{l}\text { 2. Kurangny } \\
\text { a } \\
\text { pengawas } \\
\text { an teknisi }\end{array}$ & & \\
\hline 3 & $\begin{array}{l}\text { Bahan dan } \\
\text { peralatan } \\
\text { pratikum } \\
\text { yang } \\
\text { menggandung } \\
\text { cairan kimia } \\
\text { ditempatkan } \\
\text { tidak sesuai }\end{array}$ & 1 & $\begin{array}{l}\text { Dapat } \\
\text { menyebabk } \\
\text { an } \\
\text { kerusakan } \\
\text { pada mesin }\end{array}$ & $\begin{array}{l}\text { 1. Kesadaran } \\
\text { mahasisw } \\
\text { a kurang } \\
\text { baik } \\
\text { dalam } \\
\text { mengikuti } \\
\text { SOP } \\
\text { pelatakan } \\
\text { bahan } \\
\end{array}$ & $2 \mathrm{~L}$ & 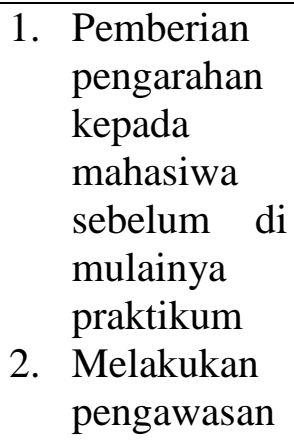 \\
\hline & & & $\begin{array}{l}\text { Dapat } \\
\text { menyebabk } \\
\text { an } \\
\text { kebakaran }\end{array}$ & $\begin{array}{l}\text { 2. Lemahnya } \\
\text { pengawas } \\
\text { an teknisi } \\
\text { dan dosen }\end{array}$ & & $\begin{array}{l}\text { pada saat } \\
\text { mahasiswa } \\
\text { melakukan } \\
\text { pratikum }\end{array}$ \\
\hline 4 & $\begin{array}{l}\text { Kabel stop } \\
\text { kontakdengan } \\
\text { kabel terurai }\end{array}$ & 1 & $\begin{array}{l}\text { Dapat } \\
\text { menyebab } \\
\text { kan } \\
\text { mahasiswa } \\
\text { tersetrum }\end{array}$ & $\begin{array}{l}\text { 1. Kurangny } \\
\text { a } \\
\text { pengawas } \\
\text { an } \\
\text { terhadap } \\
\text { sistem } \\
\text { kelistrikan }\end{array}$ & $2 \mathrm{M}$ & $\begin{array}{l}\text { 1. Pemasangan } \\
\text { cable } \\
\text { duct/tray } \\
\text { cablesebagai } \\
\text { pelindung } \\
\text { stop kontak } \\
\text { 2. Pengajuan }\end{array}$ \\
\hline & & & & $\begin{array}{l}\text { 2. Kurangny } \\
\text { a dana } \\
\text { dan } \\
\text { tindakan } \\
\text { perawatan } \\
\text { laboratori } \\
\text { um }\end{array}$ & & $\begin{array}{l}\text { dana } \\
\text { perawatan }\end{array}$ \\
\hline 5 & $\begin{array}{l}\text { Penempatan } \\
\text { barang- } \\
\text { barang } \\
\text { pribadi } \\
\text { teknisi yang } \\
\text { sembarangan }\end{array}$ & 1 & $\begin{array}{l}\text { Dapat } \\
\text { menyebabk } \\
\text { an } \\
\text { mengangg } \\
\text { u proses } \\
\text { praktikum }\end{array}$ & $\begin{array}{l}\text { 1. Kurangny } \\
\text { a } \\
\text { pemaham } \\
\text { an } \\
\text { mahasisw } \\
\text { a dan } \\
\text { teknisi } \\
\text { mengenai } \\
\text { tata letak } \\
\text { bengkel }\end{array}$ & $1 \mathrm{~L}$ & $\begin{array}{ll}\text { 1. } & \text { Membuat } \\
\text { SOP } \\
\text { peletakan } \\
\text { barang- } \\
\text { barang milik } \\
\text { teknisi dan } \\
\text { mahasiswa } \\
\text { 2. Memberikan } \\
\text { teguran } \\
\text { langsung }\end{array}$ \\
\hline & & & Dapat & 2. Lemahnya & & terhadap \\
\hline
\end{tabular}

Analisis Hiraaspek Keselamatan dan Kesehatan Kerja (K3) di Laboratorium Motor Bakar Politeknik Negeri Subang

(Adhan Efendi, Yohanes Sinung Nugroho, Muhammad Fahmi) 


\begin{tabular}{|c|c|c|c|c|c|}
\hline & & $\begin{array}{l}\text { menyebabk } \\
\text { an cidera } \\
\text { pada } \\
\text { mahasiswa } \\
\text { disaat } \\
\text { praktikum }\end{array}$ & $\begin{array}{l}\text { pengawas } \\
\text { an } \\
\text { terhadap } \\
\text { standar } \\
\text { alat dan } \\
\text { bahan }\end{array}$ & & $\begin{array}{l}\text { pelanggaran } \\
\text { yang } \\
\text { dilakukan }\end{array}$ \\
\hline \multirow[t]{2}{*}{6} & \multirow[t]{2}{*}{$\begin{array}{l}\text { Peletakan alat } \\
\text { pratikum } \\
\text { sembarangan }\end{array}$} & $\begin{array}{l}\text { 1. } \\
\text { Dapat } \\
\text { anenyebabk } \\
\text { rusaknya } \\
\text { alat praktik }\end{array}$ & $\begin{array}{l}\text { 1. Kurangny } \\
\text { a } \\
\text { pengawas } \\
\text { an dari } \\
\text { dosen dan } \\
\text { teknisi }\end{array}$ & $1 \mathrm{~L}$ & $\begin{array}{l}\text { 1. } \\
\text { Perlunya } \\
\text { jadwal } \\
\text { pengawasan } \\
\text { rutin dari } \\
\text { teknisi dan } \\
\text { dosen }\end{array}$ \\
\hline & & $\begin{array}{ll}\text { 2. } & \text { Mengangg } \\
\mathrm{u} \text { proses } \\
\text { praktikum } \\
\text { mahasiswa }\end{array}$ & $\begin{array}{l}\text { 2. Kurangny } \\
\text { a } \\
\text { pengaraha } \\
\mathrm{n} \text { sebelum } \\
\text { dan } \\
\text { sesudah } \\
\text { praktikum }\end{array}$ & & $\begin{array}{ll}\text { 2. } & \text { Pembuatan } \\
\text { SOP sesudah } \\
\text { dan sebelum } \\
\text { praktikum }\end{array}$ \\
\hline 7 & $\begin{array}{l}\text { Peralatan } \\
\text { P3K } \\
\text { diletakan di } \\
\text { lantai }\end{array}$ & $\begin{array}{l}\text { 1. Dapat } \\
\text { menyebabk } \\
\text { an } \\
\text { terganggun } \\
\text { ya proses } \\
\text { pertolongan } \\
\text { pertama }\end{array}$ & $\begin{array}{l}\text { 1. Belum } \\
\text { diterapkan } \\
\text { nya SOP } \\
\text { standar } \\
\text { P3K }\end{array}$ & $1 \mathrm{~L}$ & 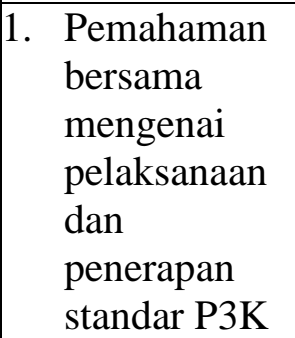 \\
\hline 8 & $\begin{array}{lr}\text { Peletakan tata } \\
\text { letak atau } \\
\text { posisi alat } \\
\text { yang tidak } \\
\text { sesuai }\end{array}$ & $\begin{array}{l}\text { 1. Dapat } \\
\text { menyebabk } \\
\text { an } \\
\text { terhambat } \\
\text { dan } \\
\text { terganggun } \\
\text { ya proses } \\
\text { pratikum } \\
\end{array}$ & $\begin{array}{l}\text { 1. Peletakan } \\
\text { mesin } \\
\text { praktikum } \\
\text { yang tidak } \\
\text { sesuai } \\
\text { kegunaan }\end{array}$ & $2 \mathrm{~L}$ & $\begin{array}{l}\text { 1. Peyusunan } \\
\text { kembali } \\
\text { posisi mesin } \\
\text { sesuai } \\
\text { dengan } \\
\text { kegunaannya }\end{array}$ \\
\hline 9 & $\begin{array}{l}\text { Peletakan } \\
\text { APAR yang } \\
\text { tidak } \\
\text { terjangkau }\end{array}$ & $\begin{array}{l}\text { 1. Dapat } \\
\text { menyebabk } \\
\text { an } \\
\text { terganggun } \\
\text { ya proses } \\
\text { pemadama } \\
\text { n } \\
\text { kebakaran } \\
\end{array}$ & $\begin{array}{l}\text { 1. Belum } \\
\text { diterapkan } \\
\text { nya SOP } \\
\text { standar } \\
\text { APAR }\end{array}$ & $1 \mathrm{~L}$ & 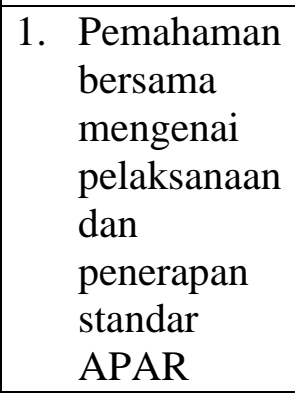 \\
\hline
\end{tabular}




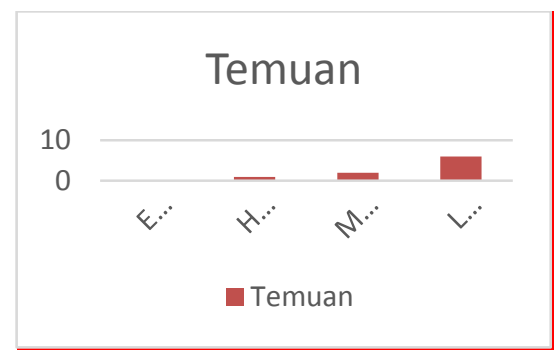

Gambar 10. grafik temuan hazard

Berdasarkan data analisis di atas dan dibandingkan dengan hasil wawancara kepada dosen, teknisi, dan mahasiswa. Dapat disimpulkan bahwa ditemukan 9 bahaya (hazard) di laboratorium motor bakar Politeknik Negeri Subang. Dari 9 bahaya tersebut terdiri dari 1 bahaya dalam kategori $3 \mathrm{H}$ (high) yaitu penempatan posisi motor terlalu berdekatan dan tidak menggunakan APD; 2 bahaya dalam kategori 2M (medium), dan 6 bahaya masuk kategori L (low). Tidak ada yang masuk dalam kategori bahaya ekstrem (E). ditambahkan oleh [7] setelah diketahui kategori bahaya tersebut, harus dilakukan penaggulangan atau pencegahan terhadap bahaya agar tidak terjadi kembali. Penangganan bahaya di mulai dari kategori E, H, M, dan L.

Penempatan posisi motor terlalu berdekatan dan tidak menggunakan APD masuk dalam kategori $3 \mathrm{H}$ (High). Hal tersebut nilai wajar dikarenakan bahaya yang ditimbulkan dapat menimbulkan cidera yang fatal. Penggunaan alat pelindung diri yang belum standar juga menjadi faktor bahaya ini di nilai sebagai bahaya level high. Berdasarkan hasil wawancara juga didapati temuan bahwa peletakan posisi motor yang berdekatan sangat menghambat proses pratikum di laboratorium. Diperjelas oleh Adhan, Aditya, dan Ridwan [12] bahwa penggunaan alat pelindung diri (APD) merupakan sesuatu hal utama dan dapat mengurangi resiko kecelakaan kerja.

Kategori bahaya yang masuk dalam level 2M (Medium)yaitu bagian stop kontak dan kabel kelistrikan yang tidak ditutup dan terurai. Bahaya ini dapat menimbulkan kecelakaan kerja yang cukup fatal, yaitu mahasiswa mengalami atau tersengat tegangan listrik. Berdasarkan hasil wawancara, para teknisi juga mengetahui bahwa hal tersebut membahayakan. Dengan alasan kurangnya anggaran perawatan laboratorium menjadi alasannya. Solusi dari hal tersebut adalah pembelian cable duct/tray cablesebagai pelindung stop kontak dan 
penataan kembali kabel yang berpotensi membahayakan. Ditambahkan oleh [5] bahaya yang telah diidentifikasi harus segera dilakukan pencegahan, hal tersebut dikarenakan bahaya dapat meningkat dari low ke medium, medium ke high, atau high ke extreme.

Kategori hazard yang masuk dalam level $1 \& 2 \mathrm{~L}($ low)yaitu hazard ditimbulkan dari kurangnya peletakan bahan-bahan, alat, K3. APAR, dan peralatan pribadi. Hazard dalam level cendrung tidak membahayakan tetapi dapat menganggu dan apabila tidak segera ditindak lanjuti, maka level bahayanya dapat meningkat. Rekomendasi bahaya level ini adalah diperlukan penataan yang lebih baik dan sesuai dengan fungsinya di masing-masing tempat.

\section{KESIMPULAN}

Berdasarkan hasil temuan dan analisis, dapat disimpulkan bahwa:

1. ditemukan 9 bahaya (hazard) di laboratorium motor bakar Politeknik Negeri Subang. Dari 9 bahaya tersebut terdiri dari 1 bahaya dalam kategori $3 \mathrm{H}$ (high) yaitu penempatan posisi motor terlalu berdekatan dan tidak menggunakan APD; 2 bahaya dalam kategori 2M (medium), dan 6 bahaya masuk kategori L (low). Tidak ada yang masuk dalam kategori bahaya ekstrem

2. Rekomendasi tindakan yang bisa dilakukan untuk mengurangi bahaya di laboratorium motor bakar Politeknik Negeri Subang yaitu pembuatan SOP laboratorium, penataan kembali tata ruang dan peralatan, serta pemberian instruksi sebelum dan sesudah mahasiswa praktikum.

\section{DAFTAR PUSTAKA}

[1] A. Efendi and Y. S. Nugroho, "Has the Electrical Laboratory of Subang State Polytechnic Applied," vol. 2, no. 2, pp. 47-52, 2019.

[2] D. P. R. dan M. Fakhri, "The Analysis Of Health And Safety Aspects By Using Hazard Identification And Risk Assessment (HIRA) Method." International Seminar On Industrial Engineering and manaement Malang, 2015, pp. 31.

[3] A. Danial, M. H. Hasyim, and S. El Unas, “Analisis Risiko Keselamatan Dan Kesehatan Kerja ( K3 ) Dengan Metode Hazard Analysis Dan Consequence - Likelihood Analysis ( Studi Kasus pada Proyek Pembangunan Gedung Baru Fakultas Ilmu Administrasi Mahasiswa / Program Sarjana / Jurusan Teknik Sipil / Fa,” 2015. 
[4] C. B. dan S. Nova, "Application Of Hira And Spar-H Method To Control Work Accident." Industrial Engineering Study Program, Faculty of Science and Technology, China, 2014.

[5] F. A. Ade Sri Mariawati, Ani Umyati, "Analisis Penerapan Keselamatan Kerja Menggunakan Metode Hazard Identification Risk Assessment ( HIRA ) Dengan Pendekatan Fault Tree Anlysis ( FTA )," vol. 3, no. 1, 2017.

[6] F. E. Saputra, “Analisis Kesesuaian Penerapan Safety Si G N di Pt . Terminal Petikemas Surabaya," pp 121-131, 2014.

[7] E. Setiawan et al., "Analisis Risiko Keselamatan dan Kesehatan Kerja Menggunakan Metode Hazard Analysis Risk Analysis of Occupational Safety and Health Using Hazard Analysis Method Musthofa, Msc," vol. 3, pp 95-103, 2019.

[8] R. Whardana, "Digital Repository Universitas Jember." Universitas Jember, Jember, 2015, pp. 98.

[9] et all Fifin Dwi Mega, "Prosiding Seminar Nasional Hasil-Hasil Penelitian Dan Pengabdian Bidang K3 2017." Universitas Sebelas Maret, Solo, 2017.

[10] B. Suhardi, P. W. Laksono, A. A. V E, J. M. Rohani, and T. S. Ching, "Analysis of the potential Hazard Identification and Risk Assessment ( HIRA ) Analysis of the Potential Hazard Identification and Risk Assessment ( HIRA ) and Hazard Operability Study ( HAZOP ) Case Study", 2018.

[11] D. J. Leggett, "Lab-HIRA : Hazard identification and risk analysis for the chemical research laboratory: Part 1 . Preliminary hazard evaluation," $J$. Chem. Heal. Saf., vol. 19, no. 5, pp 9-24, 2017.

[12] A. Efendi, A. Nugraha, and R. Baharta, "Manufacturing of Electrical Dryer Machine for Food and Fruit Products Manufacturing of Electrical Dryer Machine for Food and Fruit Products," 2019.

Analisis Hiraaspek Keselamatan dan Kesehatan Kerja (K3) di Laboratorium Motor Bakar Politeknik Negeri Subang

(Adhan Efendi, Yohanes Sinung Nugroho, Muhammad Fahmi) 